\title{
Impact of Demand Side Management on Angular Stability of Power Systems with Renewable Generation
}

DOI:

10.1109/ISGTEurope.2018.8571724

\section{Document Version}

Accepted author manuscript

Link to publication record in Manchester Research Explorer

\section{Citation for published version (APA):}

Wang, M., Hasan, K., \& Milanovic, J. V. (2018). Impact of Demand Side Management on Angular Stability of Power Systems with Renewable Generation. In 2018 IEEE PES Innovative Smart Grid Technologies Conference Europe (ISGT-Europe) https://doi.org/10.1109/ISGTEurope.2018.8571724

\section{Published in:}

2018 IEEE PES Innovative Smart Grid Technologies Conference Europe (ISGT-Europe)

\section{Citing this paper}

Please note that where the full-text provided on Manchester Research Explorer is the Author Accepted Manuscript or Proof version this may differ from the final Published version. If citing, it is advised that you check and use the publisher's definitive version.

\section{General rights}

Copyright and moral rights for the publications made accessible in the Research Explorer are retained by the authors and/or other copyright owners and it is a condition of accessing publications that users recognise and abide by the legal requirements associated with these rights.

\section{Takedown policy}

If you believe that this document breaches copyright please refer to the University of Manchester's Takedown Procedures [http://man.ac.uk/04Y6Bo] or contact uml.scholarlycommunications@manchester.ac.uk providing relevant details, so we can investigate your claim.

\section{OPEN ACCESS}




\title{
Impact of Demand Side Management on Angular Stability of Power Systems with Renewable Generation
}

\author{
Mengxuan Wang, Kazi N. Hasan, Member, IEEE, and Jovica V. Milanović, Fellow, IEEE \\ School of Electrical and Electronic Engineering \\ The University of Manchester \\ Manchester, United Kingdom \\ mengxuan.wang@postgrad.manchester.ac.uk, kazi.hasan@manchester.ac.uk, milanovic@manchester.ac.uk
}

\begin{abstract}
Demand side management (DSM) is becoming a widely considered option to enhance the operational flexibility of power systems with penetration of renewable energy resources (RES). The implementation of DSM however, could endanger power system stability as it changes the amount, type and characteristic of system demand at the transmission level. The impact of various levels of DSM on power system angular stability has been studied in this paper. The impact of uncertainties associated with RES, system loading and fault location and duration have all been considered. The results show that depending on the level of application, the DSM could either improve or reduce small and large disturbance stability of the network and that while improving one, it may deteriorate the other. All simulations are carried out in DIgSILENT/PowerFactory environment using a modified version of the 68 bus NETS-NYPS test system.
\end{abstract}

Index Terms - Angular stability, demand side management, probabilistic analysis, renewable energy resources.

\section{INTRODUCTION}

In response to raising awareness of climate change, energy crisis and sustainable development, a large amount of renewable generators have been (or will be) integrated into electrical power systems. While renewable energy resources (RES) reduce the emission of greenhouse gases significantly; they, at the same time, introduce significant amount of uncertainties into electrical power systems due to their stochastic and intermittent nature of operation. Subsequently, these uncertainties bring many operational problems and challenges for power system operation.

The connection of RES changes the dynamic behaviour of the system and such, among the others, affects system angular stability [1,2]. The effect of RES on system angular stability has been studied in the past and reasonably widely reported. For example, the adverse effect of wind integration on smalldisturbance stability has been assessed in [3]; [4] investigated transient stability of the system with renewable generators having fault-ride-through capability. The interaction between angular stability and RES has been analysed in [5], etc.

While analysing the impact of RES integration on power system angular stability, all the above mentioned studies [2-5] investigated the contribution and control of generation-side, by totally ignoring the contribution and control from the demand-side. In modern renewable intensive power systems, it becomes very important to investigate the impact of demand-side participation on power system performance to provide operational flexibility and to maintain stability [6]. Hence, this paper focuses on the analysis of the impact of demand side management (DSM) on angular stability of systems with large penetration of RES.

DSM is the modification of demand-side energy consumption patterns through various methods. Load curtailment, as one of the most common DSM methods, can reduce load demand at certain time periods in order to compensate for the imbalance between generation and load. The impact of DSM on voltage stability has been studied by applying under frequency load shedding [6] and using an iterative linear programming algorithm [7]. Also, the influence of DSM on power system frequency stability has been reported in [8-10]. Though several studies have been performed in the past to assess the impact of DSM on power system voltage and frequency stability, there are no, to the best of our knowledge, publicly available results of research into the effect of DSM on power system angular stability.

This paper implements a probabilistic framework for assessing the impact of DSM on angular stability of power systems with a high penetration of RES. The uncertainties associated with the RES, system loading and system faults have all been modelled in this study. All simulations are performed in DIgSILENT/PowerFactory environment using a modified version of the 68 bus NETS-NYPS test system and loading scenarios developed in previous research. The paper is organised as follows: Section II presents the theory of the impact of DSM and provides information about power system angular stability. Section III introduces the test system model, uncertainties, probabilistic analysis method, and study cases being used in this research. Section IV demonstrates the simulation results by highlighting the main findings from the results. The conclusions are summarised in Section V. 


\section{ACCEPTED VERSION OF THE PAPER}

\section{CONTRIBUTION OF DSM ON ANGULAR STABILITY}

\section{A. Contribution of DSM to Power System Stability}

System loading in power systems changes either as an almost continuous small variation due to regular customer activities or more rarely as sudden disturbances caused by abrupt load changes. It has been recognized that system loading can have notable influence on the angular stability of a power system and that high system loading can lead to system instability [11-14].

Due to the fact that most power system stability issues are caused by an imbalance between power generation and load, the target of improving power system stability can be achieved by implementing DSM. The DSM scheme can be developed by load shifting (i.e. load curtailment during peak-load hours and load increment during off-peak-load hours). The implementation of DSM is expected to reduce the stress on power systems during peak and off-peak hours and can compensate for the imbalance between power generation and load. Subsequently, the system with low stress will provide a better dynamic performance following a disturbance in the network. It has been assumed in this study that system inertia will not reduce as a consequence of connection of RES, i.e., the synchronous machines will be de-loaded not disconnected following the integration of RES.

\section{B. Power System Angular Stability}

Angular stability of a power system refers to the ability of synchronous machines in interconnected networks to remain in synchronism after being subjected to a large disturbance [15]. It can be further divided into small-disturbance stability and large-disturbance (transient) stability [15].

The general methodology used for studying power system angular stability follows three steps, which are: (a) injecting a disturbance into the power system (for large disturbance stability), (b) recording system angular performances by running a modal analysis for small-disturbance stability and RMS simulation for transient stability, and then, (c) calculating corresponding stability indices. Indices adopted in this research are the damping of the most critical electromechanical mode as presented in (1) and transient stability index (TSI) as presented in (2) to represent smalldisturbance stability and transient stability, respectively.

$$
\begin{gathered}
\lambda=\sigma+j \omega \\
\text { TSI }=100 \times \frac{360-\delta_{\max }}{360+\delta_{\max }}
\end{gathered}
$$

Damping of the most critical (least damped) electromechanical mode can be obtained from the corresponding eigenvalue as shown in Eq. (1), where $\lambda$ is the eigenvalue corresponding to the most critical mode and $\sigma$ is the damping (real part) of that mode. TSI can be calculated based on Eq. (2), where $\delta_{\max }$ is the maximum angle deviation between any two generators during the study time [4]. The indices above quantify the system angular stability in such a way that the system stability is better if the damping $(\sigma)$ of the most critical electromechanical mode and the TSI values are larger.

\section{TEST NETWORK AND METHODOLOGY}

\section{A. Test System Model}

The test system model adopted in this research is a modified version of the IEEE 68-bus NETS-NYPS system, which is a transmission level model that contains 5 areas, 68 buses, 16 synchronous machines, 10 wind turbines, 10 photovoltaic (PV) units and 35 loads modelled as constant impedance loads. The system model is shown in Fig. 1 where RES resources (i.e. wind and PV) are distributed in 10 buses of the network. More details of the test system model can be found in [16] and [17].

In total 12 loads (out of 35) at buses 33, 36, 40, 41, 42, 50, $52,56,59,60,61$ and 64 are considered as large industrial customers, and the remaining loads are considered as points of connection of distribution network (DN). The above mentioned loads are categorised based on their demand sizes, loads with large demand values are categorised as DNs and loads with small demand values are categorised as large industrial customers. Normalised daily load curves for large industrial customers and DNs are shown in Fig. 2 (dashed line and solid line, respectively) [18]. All RES generators are also following their daily output curves extracted from real weather measurement data [19, 20]. Normalised daily RES output curves are also shown in Fig. 2 (dotted line: wind and dash-dot line: PV). Furthermore, normalised system load curve which combine the contribution of both large industrial customers and DNs is shown as Fig. 3. In Fig. 2 and Fig. 3, all curves are normalised by their corresponding maximum value during the day. These per unit values have been scaled up to their actual values by multiplying by their rated capacity.

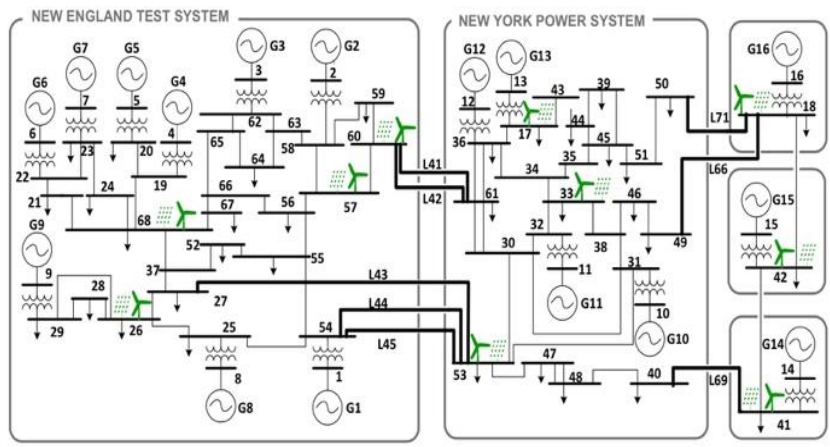

Figure 1. Modified 68 bus NETS-NYPS test system

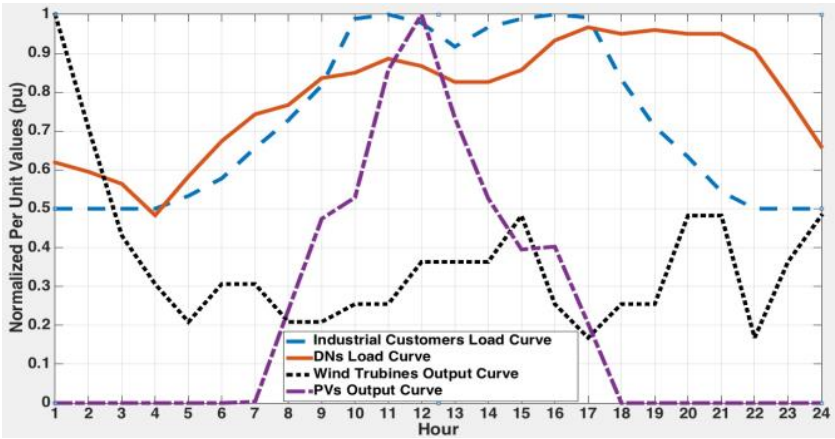

Figure 2. Normalised daily loading (large industry and DN) and RES (wind and PV) profile [18-20] 


\section{ACCEPTED VERSION OF THE PAPER}

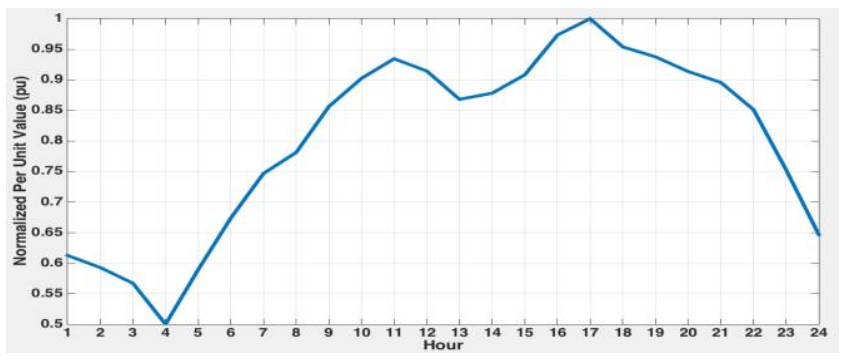

Figure 3. Normalised daily system loading profile [18]

\section{B. Power System Angular Stability}

Uncertainties from the RES, load demands and system disturbances have been considered in this simulation study. The probability distributions of these uncertainties with corresponding modelling parameters are shown in Table I.

As shown in Table I, the wind speed follows a Weibull distribution with $\alpha=2.2$ and $\beta=11.1$ [21], the PV output follows a Beta distribution [22] with $a$ parameter equal to 13.7 and $b$ parameter equal to 1.3 [23]. At each hour during the day, the load demand is considered to follow a normal distribution with mean value according to the load curve as shown in Fig. 2 and standard deviation 3.33\% [24]. Both RES and load demand uncertainties generate extra scaling factors which are multiplied with real power consumption values and real power generation values obtained from daily loading or RES profile [4]. Last but not least, fault lines and fault locations are selected randomly; the fault duration follows a normal distribution with a mean value of 13 cycles and a standard deviation of $6.67 \%$ [25].

\section{Probabilistic Analysis Method}

The simulation study is performed by considering the daily loading and RES generation patterns as shown in Fig. 2. The daily load and RES profile has been segmented into 24 hourly values and a probabilistic simulation is conducted for each hour. Hence, at each hour of the test day, two separate Monte Carlo simulations were carried out for small-disturbance and transient stability. The dynamic simulation is performed in DigSILENT PowerFactory software. Modelling of uncertainties and optimal power flow (OPF) were performed in Matpower [26]. The whole algorithm is shown in Fig. 4.

As shown in Fig. 4, at each hour during the day, result files containing system conventional generator outputs and system uncertainties are produced in Matlab for further Monte Carlo simulation runs. Load demand, RES outputs and system disturbance profiles follow their corresponding probability distributions as discussed in the previous subsection except outputs of conventional generators, which are determined by the OPF.

All result files are then imported into the DigSILENT PowerFactory for dynamic simulation. As a result of the Monte Carlo simulation at each hour, both small-disturbance and transient stability studies generate a set of stability indices. The mean value of the relevant stability indices is chosen in this study to illustrate the corresponding angular stability performance at particular hour, through other values, e.g., maximum, most probable, 95 percentile or median values could have been used as well.

\section{Study Cases}

In order to study the effect of RES penetration level and DSM on system angular stability, six study cases have been developed as shown in Table II.

TABLE I

PORBABILITY DISTRIBUTIONS AND CORRESPONDING PARAMETERS OF SYSTEM INPUT UNCERTAINTIES [21-25]

\begin{tabular}{|c|c|c|}
\hline $\begin{array}{c}\text { Input } \\
\text { Uncertainties }\end{array}$ & $\begin{array}{c}\text { Probability } \\
\text { Distributions }\end{array}$ & Modelling Parameters \\
\hline Wind Speed & Weibull Distribution & $\alpha=2.2, \beta=11.1$ \\
\hline PV Output & Beta Distribution & $\mathrm{a}=13.7, \mathrm{~b}=1.3$ \\
\hline Load Demand & Normal Distribution & $\begin{array}{c}\text { Mean value based on } \\
\text { load curves, } \sigma= \\
3.33 \%\end{array}$ \\
\hline Fault Line & Randomly & - \\
\hline Fault Location & Randomly & - \\
\hline Fault Duration & Normal Distribution & $\begin{array}{c}\text { Mean }=13 \text { cycles, } \sigma= \\
6.67 \%\end{array}$ \\
\hline
\end{tabular}

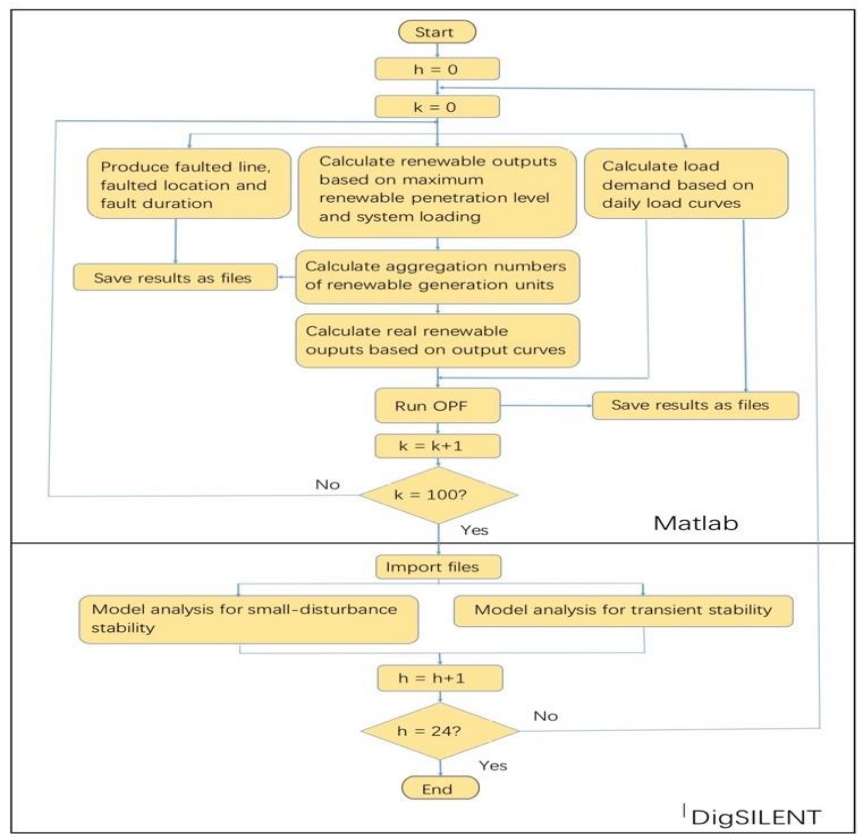

Figure 4. Representative algorithm for probabilistic angular stability analysis

TABLE II

StUdy CASES AdoPTED IN THE RESEARCH PROCESS

\begin{tabular}{|c|c|c|c|}
\hline $\begin{array}{c}\text { Case } \\
\text { Number }\end{array}$ & $\begin{array}{c}\text { Maximum RES } \\
\text { Penetration }\end{array}$ & $\begin{array}{c}\text { System } \\
\text { Loading } \\
\text { Level }\end{array}$ & DSM Application \\
\hline Case 1 & $0 \%$ & $100 \%$ & No \\
\hline Case 2 & $30 \%$ & $100 \%$ & No \\
\hline Case 3 & $50 \%$ & $100 \%$ & No \\
\hline Case 4 & $50 \%$ & $60 \%$ & $\begin{array}{c}\text { Four selected loads reduced } \\
\text { by 40\%, simultaneously, at } \\
\text { four selected hours }\end{array}$ \\
\hline Case 5 & $50 \%$ & $100 \%$ & $\begin{array}{c}\text { Four selected loads reduced } \\
\text { by 0\% to 30\% in a step of } \\
2 \%, \text { simultaneously, at four } \\
\text { selected hours }\end{array}$ \\
\hline Case 6 & $50 \%$ & $100 \%$ & \\
\hline \multicolumn{3}{|c|}{ Note: The system inertia is the same in all study cases } \\
\hline
\end{tabular}




\section{ACCEPTED VERSION OF THE PAPER}

Case 1 is the base case, which provides system angular stability references. Cases 2 and 3 are developed to study the impact of RES penetration levels on system angular stability. The maximum level of RES penetration is achieved when all aggregated RES units operate at their rated capacity. Due to the existence of daily RES output curves, maximum RES penetration levels for all cases cannot be achieved. The Case 4 is developed to study the impact of system loading on angular stability, where system de-loading is achieved by reducing all load demands by $40 \%$. Cases 5 and 6 are produced to study the impact of DSM on system angular stability. Four loads (load 17, 18, 41 and 42) have been selected to apply the DSM. These loads have been identified as the four most critical and influential loads with respect to their impact on the system small-disturbance stability [27, 28]. In Cases 5 and 6, the relevant hours for the implementation of DSM are different. In Case 5, the DSM occurs at four hours (hours 5, 12, 17 and 22) and in Case 6, DSM occurs at two selected hours (hours 17 and 22) The DSM application hours are selected based on the obtained simulation results, which will be further discussed in detail in the next section.

\section{RESULTS AND ANALYSIS}

\section{A. Impacts of RES on System Angular Stability}

Due to the application of probabilistic analysis methods, a high number of simulation results are produced at each hour. The results of the small-disturbance stability analysis of Case 1 have been shown in Fig. 5 as boxplots. The figure shows the variation of damping of the most critical electromechanical mode at each hour. By comparing Fig. 3 and 5, it can be seen that the damping values follow the trend of daily system loading profile, i.e. better (more negative) damping can be seen at low system loading (hour 4) and lower (less negative) damping values during high system loading (hours 11 and 17). Moreover, the variation in damping is slightly larger at higher system loading. In order to compare the difference between the angular stability performances of each case, mean value curves of damping and TSI of each case are adopted, which can provide better clarity.

The impacts of RES on power system angular stability can be observed from the simulation results of Cases 1,2 and 3, as presented in Fig. 6 and 7. The mean values of damping and TSI over 24 hours of a day have been shown in Fig. 6 and 7 respectively. As shown in Fig. 6, the integration of RES can improve system small-disturbance stability and this improvement increases with the rise of RES penetration levels. As mentioned previously, it has been assumed that RES connection does not lead to disconnection of synchronous machines and reduction of system inertia. As synchronous machines are de-loaded with the increase of RES penetration level, it results in more spare capacities, which ultimately may improve the system stability. A significant improvement of system small-disturbance stability can be obtained at hour 1, when all renewable powers are injected by wind turbines and all wind turbines operate at their maximum daily output (as shown in Fig. 2). At hour 12, the mean damping value of Case 3 is slightly higher than that of Case 2, which shows that the higher RES penetration level doesn't improve system small-disturbance stability further at hour 12 . Due to the inconsistent result obtained at hour 12, this hour is selected as one of four DSM application hours in Case 5.

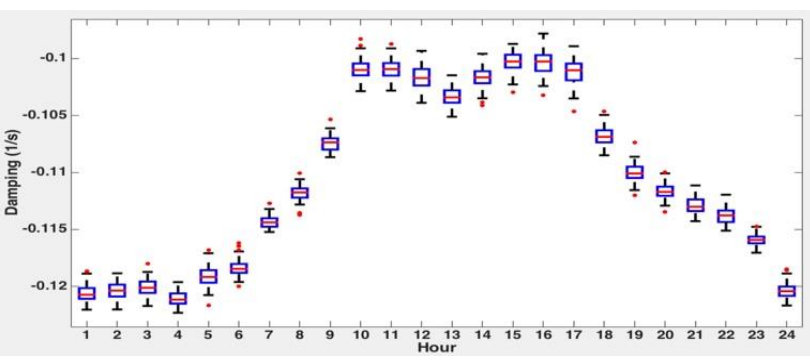

Figure 5. Boxplot of damping results of Case 1

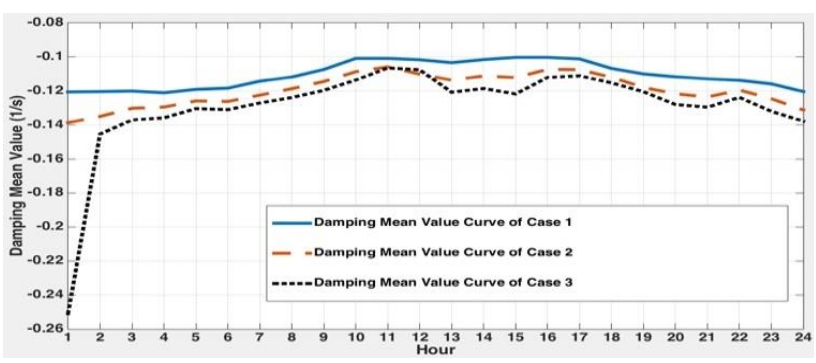

Figure 6. Small-disturbance stability results of Case 1 (no RES), Case 2 (30\% RES) and Case 3 (50\% RES)

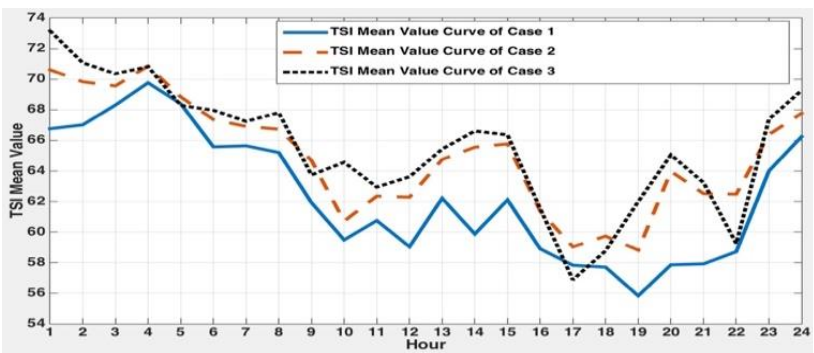

Figure 7. Transient stability results of Case 1 (no RES), Case 2 (30\% RES) and Case 3 (50\% RES)

In terms of the general trend of the change in transient stability, from Fig. 7, it can be seen that the integration of RES can improve system transient stability most of the time. When the RES penetration level is $30 \%$ (Case 2), system transient stability is improved all the time (compared to Case 1, where there was no RES). Specifically, significant improvement can be noticed at hours 1 to 3 , hours 12 to 15 and hours 19 to 22 . However, when the RES penetration has been increased to $50 \%$ (Case 3), the change of TSI becomes more irregular, through a general trend of TSI increase is observed. At hours 5 and 17, the mean value of TSI in Case 3 is lower than that of Case 1. Furthermore, at hour 22, the mean values of TSI in Cases 1 and 3 are really close to each other. At these three hours, there are negative, or no, effects of transient stability due to the connection of RES. Therefore, these three hours have been selected to be the timespan of the DSM application in Case 5.

\section{B. Impacts of System Loading on System Angular Stabiltiy}

In order to combine the effects of RES and system loading on system angular stability, a 3-D surface plot is produced as shown in Fig. 8. Fig. 8 is plotted based on the mean values of damping and TSI for Cases 1, 3 and 4, where the black surface, the white surface and the gray surface represents the angular stability of Cases 1, 3 and 4, respectively

It can be seen from Fig. 8 that the white surface is below the black surface except for some ripples, which means the 


\section{ACCEPTED VERSION OF THE PAPER}

system angular stability can be improved with the integration of RES. But during some hours of the day, the amount of RES may lead to decreased power system angular stability. The distance between the black surface and the white surface can be defined as the increase of system flexibility due to the connection of RES. Then, the effects of RES penetration levels on system angular stability can be quantified. When the whole system is de-loaded by $40 \%$, there are no intersections between the surfaces of Cases 1 and 4, and angular stability is completely improved throughout the day as a consequence of the connection of RES and system de-loading. System deloading can further improve system angular stability when the RES penetration level is high because system de-loading can lead to more spare capacities and stability support from deloaded synchronous machines.

\section{Impact of DSM on System Angular Stability}

In order to investigate the impact of DSM on power system angular stability with a high penetration of RES, Case 5 is developed. As mentioned previously, DSM is applied at four selected (most influential) loads (loads 17, 18, 41 and 42) and four selected hours (hours 5, 12, 17 and 22). In Case 5, DSM is applied by reducing all selected loads by $40 \%$ at four selected hours, The DSM operation has been kept active for the entire hour.

When a $40 \%$ DSM is applied to the four largest loads in the system, small-disturbance stability simulation results and transient stability simulation results are shown in Fig. 9 and Fig. 10, respectively. It can be seen from Fig. 9, that mean values of damping of the most critical electromechanical mode decrease significantly (hours 5 and 12) and even become positive (hours 17 and 22) during DSM application hours. Hence, some un-planned DSM may have a negative impact on power system angular stability. The situation regarding transient stability, however, is the opposite. Significant improvements of TSI, hence transient stability of the system, can be seen at DSM application hours (hours 5, 12, 17 and 22).

In summary, small-disturbance stability of the system could be negatively affected by high level of DSM (40\%) while the transient stability gets improved.

\section{Sensitivity of System Angular Stability to DSM}

The sensitivity of power system angular stability on the level of DSM has been studied by applying a variable level of DSM ( $0 \%$ to $30 \%$ in a step of $2 \%$ ) (Case 6). DSM has been applied to the same four loads at hours 17 and 22 due to potential stability concerns resulting from DSM application (Fig. 9). The mean values of damping and TSI with different DSM capacities are shown in Fig. 11 and Fig. 12, respectively.

Based on Fig. 11, it can be seen that the mean values of damping decrease with the increase of DSM capacity when the DSM capacity is relatively small. This demonstrates that small-disturbance stability can be improved when the DSM capacity is relatively low. However, if the DSM capacity is more than $16 \%$ at hour 17 and more than $20 \%$ at hour 22, the mean values of damping decrease rapidly and the system becomes unstable. Hence, a high level of DSM can endanger system small-disturbance stability, at some hours of the day (e.g., at 17:00 in Fig. 11).

On the other hand, it can be seen from Fig. 12 that the mean value of TSI has been improved when the DSM

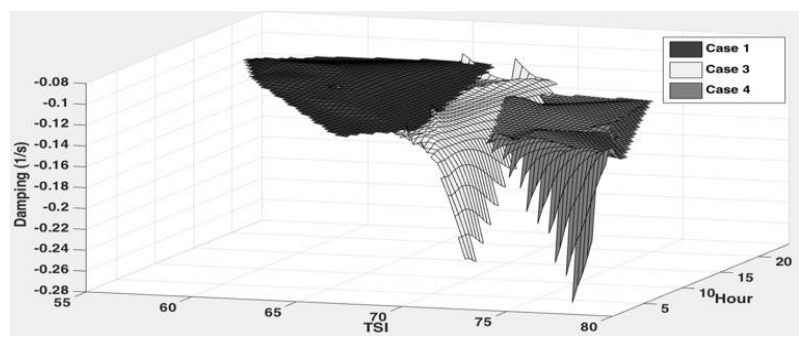

Figure 8. Surface (3-D) plot of angular stability considering Case 1 (no RES, $100 \%$ loading), Case 3 (50\% RES, 100\% loading) and Case 4 (50\% RES, $60 \%$ loading)

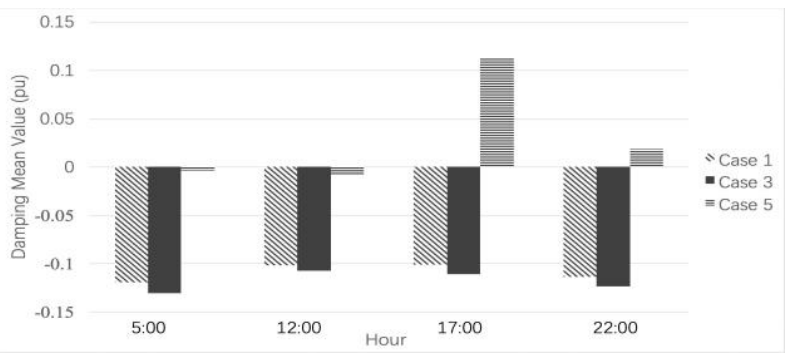

Figure 9. Small-disturbance stability results of Case 1 (no RES), Case 3 (50\% RES) and Case 5 (50\% RES, 40\% DSM)

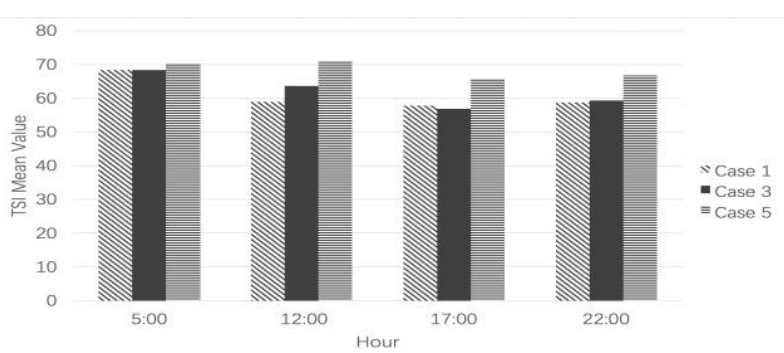

Figure 10. Transient stability results of Case 1 (no RES), Case 3 (50\% RES) and Case 5 (50\% RES, 40\% DSM)

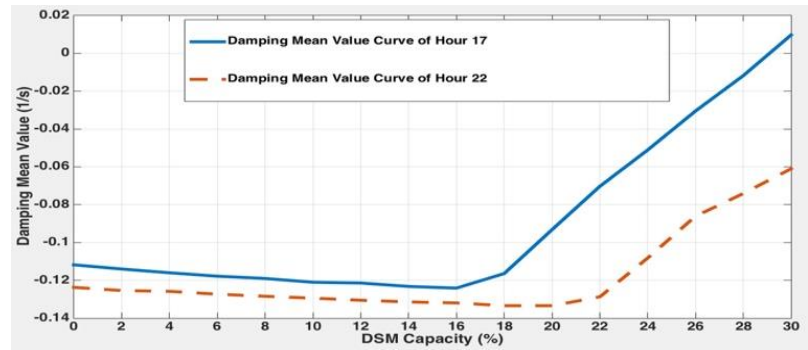

Figure 11. Damping with variable DSM capacities at hours 17 and 22

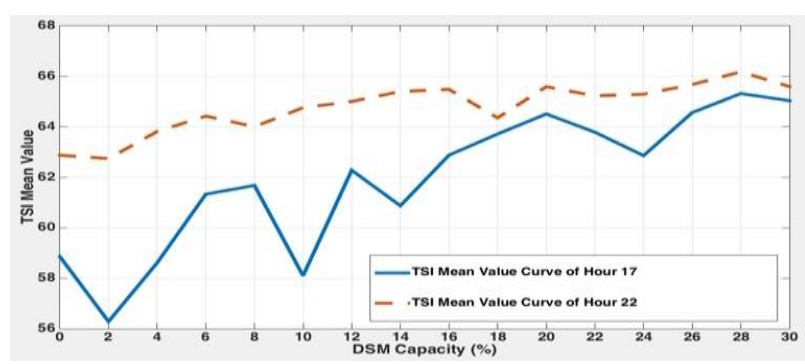

Figure 12. TSI with variable DSM capacities at hours 17 and 22

capacities are relatively high. At 17:00, TSI improves once the DSM capacity is $10 \%$ and higher. However, when the DSM capacity is low $(2 \%, 4 \%$ and $10 \%)$, there might be some negative effects on transient stability. At 22:00, TSI can be improved when the DSM capacity exceeds $2 \%$ and these improvements are increasing with the increase of DSM 


\section{ACCEPTED VERSION OF THE PAPER}

capacity most of the time. Therefore, unlike small-disturbance stability, transient stability improves with higher DSM capacity.

In summary, for the test system considered, low DSM capacities improve system small-disturbance stability while high DSM capacities can endanger it. On the other hand, system transient stability benefits from high DSM capacities and it may get deteriorated by low DSM capacities.

\section{CONCLUSIONS}

This paper has demonstrated the impacts of RES penetration levels, system loading and DSM on power system angular stability. The probabilistic simulation has been performed over 24 hours of a day with the consideration of system uncertainties from generations, load demands and fault profiles. It has been found that the integration of RES in the system can improve system both small-disturbance stability and transient stability most of the time. System de-loading can further improve system angular stability when the RES penetration level is high.

In terms of DSM, it has been found that small-disturbance stability can be improved with low levels (small amount of load disconnected) of DSM; however, it becomes worse with high levels (significant portion of load disconnected) of DSM. On the other hand, transient stability can be improved following high levels of DSM while when the DSM capacities are relatively low, transient stability could be endangered. Clearly a trade-off is needed when selecting the DSM capacity in order to achieve overall benefit for system angular stability.

\section{ACKNOWLEDGEMENT AND DISCLAIMER}

This research is supported by the EU H2020 project CROSSBOW (Grant Agreement no. 773430). The test network and the loading scenarios used in this study were originally developed by Dr A. Adrees and Dr P. Papadopoulos as a part of their research.

This paper reflects only the author's views and neither the Agency nor the Commission are responsible for any use that may be made of the information contained therein.

\section{REFERENCES}

[1] A. Atputharajah and T. K. Saha. "Power System Blackouts - Literature review," Fourth International Conference on Industrial and Information Systems, ICIIS 2009, 28-31 December 2009, Sri Lanka.

[2] U. Munz and M. Metzger. "Voltage and Angle Stability Reserve of Power Systems with Renewable Generation," $19^{\text {th }}$ World Congress, The International Federation of Automatic Control. vol. 47, iss. 3, pp. 9075-9080, 2014

[3] W. Du, J. Bi, C. Lv and T. Littler. "Damping torque analysis of power systems with DFIGs for wind power generation," IET Renew. Power Gener., vol. 11, iss. 1, pp. 10-19, 2017.

[4] P. N. Papadopoulos and J. V. Milanovic. "Probabilistic Framework for Transient Stability Assessment of Power Systems with High Penetration of Renewable Generation," IEEE Trans. Power Systems. vol. 32, pp. 3078-3088, July 2017.

[5] C. Chen, W. Du, S. Q. Bu and H. F. Wang. "Probabilistic rotor angular stability considering renewable power generations - a survey," IET Renew. Power Gener., 2015.

[6] Y. Dong, X. Xie, K. Wang, B. Zhou and Q. Jiang. "An EmergencyDemand-Response Based Under Speed Load Shedding Scheme to Improve Short-Term Voltage Stability," IEEE Trans. Power Systems, vol. 32, pp. 3726-3735. Sept. 2017.

[7] M. Yao, J. L. Mathieu and D. K. Molzahn. "Using Demand Response to Improve Power System Voltage Stability Margins".
[8] H. W. Qazi and D. Flynn. "Analysing the impact of large-scale decentralized demand side response on frequency stability," ELSEVIER. Electrical Power and Energy Systems 80 (2016) 1-9.

[9] G. Benysek, J. Bojarski, M. Jarnut and R. Smolenski. "Decentralized Active Demand Response (DADR) system for improvement of frequency stability in distribution network," ELSEVIER. Electrical Power Systems Research 134 (2016) 80-87.

[10] J. A. Short, D. G. Infield and L. L. Freris. "Stabilization of Grid Frequency Through Dynamic Demand Control," IEEE Trans. Power Systems, vol. 22, pp. 1284-1293, July 2007.

[11] I. A. Hiskens and J. V. Milanovic, "Load modelling in studies of power system damping," IEEE Trans. Power Syst., vol. 10, no. 4, pp. 17811788, 1995.

[12] J. V. Milanovic and I. A. Hiskens, "Effects of load dynamics on power system damping," IEEE Trans. Power Syst., vol. 10, no. 2, pp. 1022$1028,1995$.

[13] P. Kundur et al., "Definition and classification of power system stability IEEE/CIGRE joint task force on stability terms and definitions," IEEE Trans. Power Syst., vol. 19, no. 3, pp. 1387-1401, 2004

[14] K. N. Hasan, R. Preece, and J. V. Milanović, "The Influence of Load on Risk-Based Small-Disturbance Security Profile of a Power System," IEEE Transactions on Power Systems, vol. 33, no. 1, pp. 557-566, 2018.

[15] P. Kundur, J. Paserba, V. Ajjarapu, G. Andersson, A. Bose, C. Canizares, N. Hatziargyrious, D. Hill, A. Stankovic, C. Taylor, T. V. Cutsem and V. Vittal. "Definition and classification of power system stability IEEE/CIGRE joint task force on stability terms and definitions," IEEE Trans. Power Systems, vol. 19, pp. 1387-1401, May 2004.

[16] G. Rogers, Power System Oscillations. Norwell, MA, USA: Kluwer, 2000.

[17] B. Pal and B. Chaudhuri, Robust Control in Power Systems. New York, NY, USA: Springer, 2005.

[18] M. Starke, N. Alkadi and O. Ma. "Assessment of Industrial Load for Demand Response across U.S. Regions of the Western Interconnect," ORNL., Oak Ridge, Tennessee, USA. Sept. 2013.

[19] The University of Edinburgh, "Matching Renewable Electricity Generation with Demand," Scottish Executive, Edinburgh, 2006.

[20] National Renewable Energy Laboratory. PVWatts Viewer [Online]. Available: http://gisatnrel.nrel.gov/PVWatters_Viewer/index.html..

[21] S. Tao, Y. Ruoying, Z. Lingzhi and G. Shan, "Power system probabilistic production simulation containing large-scale wind power and photovoltaic power," in Proc. IEEE PES Asia-Pacific Power Energy Eng. Conf., Dec. 8-11, 2013, pp. 1-6.

[22] M. Fan, V. Vittal, G. Heydt and R. Ayyanar, "Probabilistic power flow studies for transmission systems with photovoltaic generation using cumulants," IEEE Trans. Power Systems, vol. 27, no. 4, pp. 2251-2261, Nov. 2012

[23] R. Preece and J. V. Milanovic, "Tuning of a damping controller for multiterminal VSC-HVDC grids using the probabilistic collocation method," IEEE Trans. Power Del., vol. 29, no. 1, pp. 318-326, Feb. 2014.

[24] T. Guo and J. V. Milanovic, "Probabilistic framework for assessing the accuracy of data mining tool for online prediction of transient stability," IEEE Trans. Power Systems, vol. 29, no. 1, pp. 377-385, Jan. 2014.

[25] T. Guo and J. V. Milanovic, "Online identification of power system dynamic signature using PMU measurements and data mining," IEEE Trans. Power Systems, vol. 31, no. 3, pp. 1760-1768, May 2016.

[26] R. D. Zimmerman, C. E. Murillo-Sanchez and R. J. Thomas, "MATPOWER: Steady-state operations, planning and analysis tools for power system research and education," IEEE Trans. Power Systems, vol. 26, no. 1, pp. 12-19, Feb. 2011.

[27] K. N. Hasan, R. Preece and J. V. Milanovic, "Efficient identification of critical parameters affecting the small-disturbance stability of power systems with variable uncertainty," Power and Energy Society General Meeting (PESGM), 2016.

[28] K. N. Hasan, R. Preece and J. V. Milanovic, "Priority ranking of critical uncertainties affecting small-disturbance stability using sensitivity analysis techniques," IEEE Trans. Power Systems, vol. 32, no. 4, pp. 2629-2639, July 2017. 